RESEARCH REPORT

\title{
Neighbourhood social participation and women's use of anxiolytic-hypnotic drugs: a multilevel analysis
}

\author{
K Johnell, J Merlo, J Lynch, G Blennow
}

J Epidemiol Community Health 2004;58:59-64

See end of article for authors' affiliations

Correspondence to: Kristina Johnell, Family Medicine Stockholm, Karolinska Institutet, Alfred Nobels allé 12, S-141 83 Huddinge, Sweden Kristina.Johnell@

klinvet.ki.se

Accepted for publication 16 May 2003

Study objectives: To identify and quantify a hypothesised collective effect of the neighbourhood on individual use of anxiolytic-hypnotic drugs (AHD). To analyse the general impact of neighbourhood social participation on use of AHD, adjusting for individual characteristics.

Design: Cross sectional analysis performed by multilevel logistic regression with women at the first level and neighbourhoods at the second level.

Setting: Malmö (250 000 inhabitants), Sweden.

Participants: 15456 women aged 45 to 73 , residing in 95 neighbourhoods in Malmö, who took part in the Malmö diet and cancer study (1991-1996).

Main results: The prevalence of AHD use was $5.5 \%$ in the study sample. Overall, $1.7 \%$ of the total individual differences in the propensity for using AHD were explained by the neighbourhood level. This percentage, however, differed between different individuals. Low level of social participation in the neighbourhood was associated with higher probability of $A H D$ use $(O R=3.10(95 \% \mathrm{Cl} 1.51$ to 6.41$))$, independently of individual age, low social participation, low educational level, and living alone. This association was reduced $(\mathrm{OR}=2.01(95 \% \mathrm{Cl} 0.97$ to 4.14$)$ ) after the additional accounting for individual disability pension, low self rated health, stress, and medication for somatic disorders.

Conclusions: The neighbourhood level of social participation seems to affect individual use of AHD, possibly through individual characteristics. However, neighbourhood boundaries play a minor part in understanding individual AHD use in the city of Malmö.

$\mathrm{P}$ eople living within the same neighbourhood may be more similar to each other than people living in other neighbourhoods; not only because similar people move to similar neighbourhoods, but also because they share neighbourhood specific economic, lifestyle and social factors, and health care availability, which may have a collective influence over and above individual circumstances.

Medication use may be determined by other factors than those strictly related to pharmacological circumstances, such as the individual patient's beliefs ${ }^{1}$ and expectations, socioeconomic resources, ${ }^{2-4}$ and those kind of factors may be shaped by the neighbourhood environment. Living in deprived neighbourhoods may affect the physical and mental health by increasing vulnerability directly or indirectly through diverse mechanisms like access to health services, normative attitudes towards health, social support, transmission of health information, and adaptation to health behaviour norms. ${ }^{5}{ }^{6}$ Such contextual factors might, in turn, condition individual medication use over and above individual characteristics. ${ }^{7}$

Social participation is an important concept for understanding the influence of social factors on individual health. Neighbourhood social participation has been considered as a structural component within the concept of social capital, a concept that is ecological in its nature. ${ }^{89}$ Both individual and community level of social participation may affect health and health related behaviour (like medication use). ${ }^{9} 10$

Firstly, this study aims to identify and quantify a hypothesised collective effect of the neighbourhood on individual use of anxiolytic-hypnotic drugs (AHD) in the city of Malmö, Sweden. Secondly, this study aims to analyse the general impact of neighbourhood social participation on use of these medicines, adjusting for individual characteristics, especially individual social participation.

Abbreviations: AHD, anxiolytic-hypnotic drugs; MDCS, Malmö diet and cancer study; ICC, intraclass correlation; VPC, variance partition coefficient; RIGLS, restricted iterative generalised least squares; PQL, penalised quasilikelihood

\section{METHODS}

\section{The Malmö diet and cancer study}

All data used in this study originate from The Malmö diet and cancer study (MDCS), a prospective cohort study ${ }^{11}$ performed in the city of Malmö in southern Sweden. The city had a population of about 250000 inhabitants in 1995 and was administratively divided into 110 neighbourhoods. In this study, we included 95 neighbourhoods, leaving out 15 neighbourhoods that each had less than 20 participants in the MDCS. We set an arbitrary limit of 20 participants to reduce bias regarding the measurement of information about the neighbourhoods.

People were requested to participate in the MDCS by letters of invitation, information through advertisements in the local media and collaboration with large employers in Malmö. In total, letters of invitation provided $80 \%$ of the participants.

The 17388 women, aged 45 to 73 years, who participated in the MDCS cohort, represented $41 \%$ of all women born 1923-1950 living in Malmö during the baseline period 19911996. Of these women, 89\% ( 15456 of 17 388) were included in this study. Reasons for exclusion were lack of information on drug use, incomplete information on other variables studied, and living in neighbourhoods with less than 20 participants in the MDCS.

Baseline examination occurred during 1991-1996. A self administered questionnaire and a seven day personal diary were used to obtain information on relevant characteristics of the women, including use of medication. The participants 
completed both information sources at home within one to two weeks between the first and the second consecutive baseline visit to the project office. ${ }^{11}$ All participants in this study gave information in both the questionnaire and the diary. Information on how many women had the questionnaire and the diary administered during 1991-1996 is presented in a previous paper. ${ }^{12}$

The ethical committee at the Medical Faculty of Lund University approved the study proposal of the MDCS and all participants gave signed informed consent. A detailed description of the design and aims of the cohort study is given elsewhere. ${ }^{11}$

\section{Outcome}

We obtained information on medication use from both the self administered questionnaire and the seven day personal diary. In the self administered questionnaire, women listed brand name(s) of the $\operatorname{drug}(\mathrm{s})$ they had used during the past two weeks. In the seven day personal diary they daily indicated the medicines they used during the week. Thereafter, all brand names were classified in accordance with the 1997 version of the Anatomical Therapeutic Chemical classification system ${ }^{13}{ }^{14}$ (ATC-97). Use of anxiolytic-hypnotic drugs (AHD) was defined by the codes N05B (anxiolytics), N05C (hypnotics and sedatives) and N03AE (benzodiazepine derivates).

\section{Explanatory variables}

Age was aggregated into four groups: 45-49 (reference), $50-59,60-69$, and $70-73$ years.

Individual social participation was defined by possible involvement in 13 formal or informal activities (study circle/ course at work place, other study circle/course, union meeting, meeting of other organisations, theatre/cinema, arts exhibition, church, sports event, letter to editor of a newspaper/journal, demonstration, night club/entertainment, large gathering of relatives, private party), which the respondent might have participated in during the previous 12 months. ${ }^{15}$ Items were summed, and participants with involvement in three or fewer activities (lowest quartile) were classified as having low social participation.

Low neighbourhood social participation was assessed by the proportion of persons in the neighbourhood who were classified as having individual low social participation.

Less than nine years of formal education was defined as low educational level.

Participants also reported whether they were living alone and whether they felt psychological stress outside the work place. All women aged less than 65 years reporting retirement were considered to have a disability pension. An ordinal scale ranging from 1 ("worst possible") to 7 ("best possible") determined self rated health (SRH). Low self rated health was defined as a value of $\leqslant 4$ on this scale. Medication for somatic disorders was defined as use of any pharmaceutical drug except those in the ATC-group N (nervous system).

\section{Statistical analysis}

We analysed dichotomous AHD use by multilevel logistic regression analysis ${ }^{16-18}$ with women at the first level and neighbourhoods at the second level. We constructed four models. The first model $i$, called the empty model, was without explanatory variables (that is, simple component of variance analysis). The second model $i i$ contained age together with one other variable at a time. The third model iii was created to observe whether social participation at the neighbourhood level affected individual AHD use, over and above the individual variables age, low educational level, low social participation, and living alone. The fourth model iv included all the studied variables.

\section{Fixed effects}

We observed the association (the slope of the regression) between individual use of AHD and different individual variables, and the neighbourhood variable percentage of people with low social participation. The $\beta$ coefficients (standard errors) were converted into odds ratios $(95 \%$ confidence intervals).

\section{Random effects}

We examined whether the neighbourhood environment affected the general individual propensity of using AHD, over and above individual characteristics. This possible contextual effect was measured by the intraclass correlation (ICC), or in this case, the intra-neighbourhood correlation. The ICC represented the percentage of the total variance in the propensity of using AHD that was related to the neighbourhood level and was also used as a measure of clustering of AHD use in the neighbourhoods. The ICC is a simple form of the "variance partition coefficient" (VPC). ${ }^{19}$ For dichotomous variables, for example, use of AHD, ICC can be calculated according to the formula used by Snijders ${ }^{16}$ (pages 223-6):

$$
\begin{aligned}
I C C & =\frac{V n}{V n+\frac{\pi^{2}}{3}} \\
V_{n} & =\text { neighbourhood variance }
\end{aligned}
$$

Calculated in this way, the ICC represents the average ICC for all individuals. ${ }^{19} 20$

A high ICC in the empty model would indicate high clustering of medication use in the neighbourhoods and strong neighbourhood effect on individual medication use. A low ICC, on the other hand, would express the existence of a weak neighbourhood influence on individual medication use.

In separate age adjusted models, we performed several multilevel logistic regression analyses with the individual variables (that is, low social participation, low educational level, living alone, disability pension, low self rated health, self reported stress, missing information on stress, and medication for somatic disorders) as dependent variables. Analyses of the ICC permitted quantification of the degree to which these individual socioeconomic and health related factors were clustered within the neighbourhoods.

In model ii we analysed cross level interactions by letting the slopes of the association between AHD use and the individual variables be random at the neighbourhood level. Random slope variance would indicate that the individual level association was modified by the neighbourhood level (that is, cross level interaction).

Parameters were estimated using the restricted iterative generalised least squares (RIGLS) and penalised quasilikelihood (PQL). Extra-binomial variation was explored systematically in all models and we found no evidence for underdispersion or over-dispersion. The MLwiN version 1.1 software package $^{21}$ was used to perform the analyses.

\section{RESULTS}

The prevalence of AHD use was 5.5\% in the study sample. Of all the 18 different AHD used by the participants, flunitrazepam was the most commonly used drug (1.3\%), followed by oxazepam $(1.3 \%)$, diazepam $(0.9 \%)$, nitrazepam $(0.8 \%)$, and propiomazine $(0.5 \%)$. AHD users had an impaired health and socioeconomic profile, with lower social participation (table 1). The median (1st-3rd quartile) neighbourhood low social participation was $29.3 \%(22.9 \%-36.7 \%)$. Table 1 shows that as the percentage of individuals with low social participation within the neighbourhoods increased from 
Table 1 Characteristics of the 15456 women residing in 95 of the 110 neighbourhoods in the city of Malmö. Values are percentages unless otherwise indicated

\begin{tabular}{|c|c|c|c|c|c|c|c|}
\hline & \multirow{3}{*}{$\begin{array}{c}\text { ICC }^{*} \\
1.7\end{array}$} & \multicolumn{2}{|l|}{ Use of AHD } & \multicolumn{4}{|c|}{$\begin{array}{l}\text { Neighbourhood quartile groups of increasing rate } \\
\text { of low social participation (mean \%) }\end{array}$} \\
\hline & & No & Yes & Group 1 & Group 2 & Group 3 & Group 4 \\
\hline & & 94.5 & 5.5 & 4.4 & 5.3 & 5.6 & 6.9 \\
\hline Age & 6.0 & $\begin{array}{l}\text { mean years } \\
573\end{array}$ & $\begin{array}{l}\text { mean years } \\
603\end{array}$ & $\begin{array}{l}\text { mean years } \\
56.2\end{array}$ & $\begin{array}{l}\text { mean years } \\
570\end{array}$ & $\begin{array}{l}\text { mean years } \\
573\end{array}$ & mean years \\
\hline $\begin{array}{l}\text { Low social } \\
\text { participation }\end{array}$ & 7.0 & 29.5 & 42.6 & 19.1 & 25.3 & 36.2 & 45.5 \\
\hline Low educational level & 14.5 & 38.7 & 42.6 & 18.8 & 33.4 & 46.0 & 61.2 \\
\hline Living alone & 20.3 & 27.7 & 41.7 & 17.0 & 21.5 & 29.4 & 38.1 \\
\hline Disability pension & 8.9 & 4.9 & 12.9 & 3.2 & 4.2 & 5.3 & 9.0 \\
\hline Low self rated health & 1.3 & 27.8 & 61.4 & 24.1 & 28.1 & 31.4 & 35.2 \\
\hline Self reported stress & 0.8 & 30.9 & 54.1 & 32.4 & 31.1 & 28.6 & 31.8 \\
\hline $\begin{array}{l}\text { Not answering the } \\
\text { question on stress }\end{array}$ & 0.1 & 5.2 & 10.2 & 4.6 & 5.7 & 4.8 & 7.1 \\
\hline $\begin{array}{l}\text { Medication for } \\
\text { somatic disorders }\end{array}$ & 0.2 & 61.7 & 83.0 & 63.2 & 64.4 & 62.6 & 61.3 \\
\hline
\end{tabular}

low (group 1) to high (froup 4), the women's health, behaviour and socioeconomic profiles were impaired. Table 1 indicates that, in average, there was a modest neighbourhood clustering of AHD use (ICC $=1.7 \%)$. Table 1 also suggests the existence of socioeconomic segregation in the neighbourhoods as illustrated by the ICC for the individual variables living alone (ICC $=20.3 \%)$, low educational level (ICC $=14.5 \%)$, low social participation $($ ICC $=7.0 \%)$, and disability pension ( ICC $=8.9 \%$ ). In contrast, the clustering was very small (ICC around $1 \%$ or less) in relation to health related variables.

\section{Fixed effects}

Neighbourhood low social participation was associated with higher individual probability of use of AHD (table 2). Model iii shows that, independently of each other, both individual and neighbourhood social participation were associated with AHD use. After inclusion of all the individual variables in

Table 2 ICC and fixed effects results from separate models showing odds ratios (OR) with $95 \%$ confidence intervals $(95 \% \mathrm{Cl})$ for neighbourhood and individual variables regarding use of anxiolytic-hypnotic drugs among 15456 women residing in 95 of the 110 neighbourhoods in the city of Malmö

\begin{tabular}{|c|c|c|c|}
\hline & ICC (\%) & Neighbourhood & variance (standard error) \\
\hline Model $i$ (empty model) & 1.7 & $0.056(0.025)$ & \\
\hline & OR & $(95 \% \mathrm{Cl})$ & $\begin{array}{l}\text { Neighbourhood slope } \\
\text { variance (standard error) }\end{array}$ \\
\hline Model ii & & & \\
\hline Age adjusted models & & & \\
\hline Age & & & \\
\hline $45-49$ & Ref & & \\
\hline $50-59$ & 1.94 & (1.54 to 2.45 ) & 0 \\
\hline $60-69$ & 2.95 & (2.34 to 3.72 ) & $0.044(0.067)$ \\
\hline $70-73$ & 2.98 & (2.27 to 3.92 ) & 0 \\
\hline Low social participation (yes $v$ no) & 1.54 & (1.33 to 1.78$)$ & 0 \\
\hline Low educational level (yes $v$ no) & 0.93 & (0.79 to 1.10 ) & $0.084(0.076)$ \\
\hline Living alone (yes $v$ no) & 1.70 & (1.45 to 1.99 ) & $0.081(0.075)$ \\
\hline Disability pension (yes $v$ no) & 3.02 & (2.42 to 3.77$)$ & \\
\hline Low self rated health (yes $v$ no) & 4.29 & (3.67 to 5.01$)$ & $0.057(0.070)$ \\
\hline Stress & & & \\
\hline Self reported stress (yes $v$ no) & 3.19 & (2.69 to 3.79 ) & $0.104(0.079)$ \\
\hline $\begin{array}{l}\text { Missing information on self } \\
\text { reported stress (yes } v \text { no) }\end{array}$ & 2.95 & (2.16 to 4.04$)$ & $0.435(0.264)$ \\
\hline $\begin{array}{l}\text { Medication for somatic disorders } \\
\text { (yes } v \text { no) }\end{array}$ & 2.91 & (2.38 to 3.56$)$ & $0.107(0.119)$ \\
\hline $\begin{array}{l}\text { Neighbourhood rate of low social } \\
\text { participation } \\
\text { Model iii }\end{array}$ & 5.02 & (2.39 to 10.55 ) & - \\
\hline Low social participation (yes $v$ no) & 1.56 & (1.34 to 1.81$)$ & \\
\hline Low educational level (yes $v$ no) & 0.81 & $(0.70$ to 0.95$)$ & \\
\hline Living alone (yes $v$ no) & 1.60 & (1.38 to 1.86$)$ & \\
\hline $\begin{array}{l}\text { Neighbourhood rate of low social } \\
\text { participation }\end{array}$ & 3.10 & (1.51 to 6.41$)$ & \\
\hline Model iv & & & \\
\hline All variables in the model & & & \\
\hline $\begin{array}{l}\text { Neighbourhood rate of low social } \\
\text { participation }\end{array}$ & 2.01 & (0.97 to 4.14 ) & \\
\hline
\end{tabular}




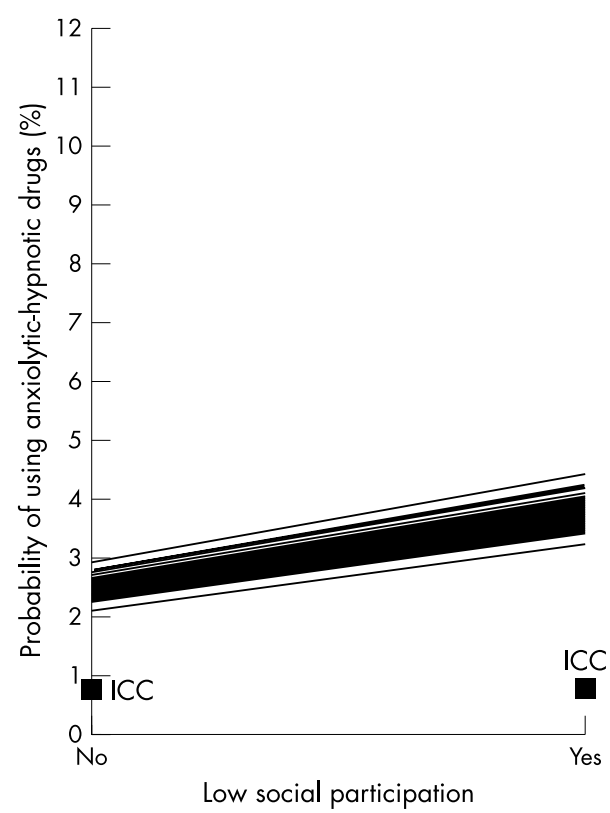

Figure 1 Age adjusted probability of using anxiolytic-hypnotic drugs, and specific intraclass correlation (black squares), in function of individual social participation among 15456 women residing in 95 of the 110 neighbourhoods in the city of Malmö.

model $i v$, the association between the neighbourhood variable and AHD use was weakened and slightly uncertain using $95 \%$ confidence intervals.

\section{Random effects}

Model $i$ (empty model) revealed that only a relatively small percentage of the total individual variability in the propensity of using AHD was attributable to the neighbourhood level $($ ICC $=1.7 \%)$.

The random slopes variance analysis suggested that the neighbourhood modified the association between certain individual level variables and AHD use (figs 1 and 2). Figure 2 shows the predicted probability of using AHD in function of self reported stress. Both the women who reported stress (ICC $=2.1 \%$ ) and those who did not answer this question $($ ICC $=11.1)$ had a higher probability of AHD use. This

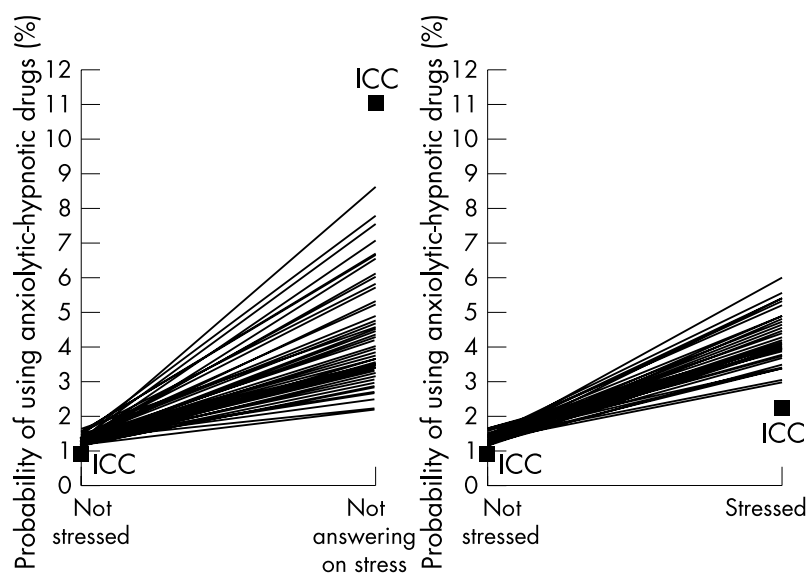

Figure 2 Age adjusted probability of using anxiolytic-hypnotic drugs, and specific intraclass correlation (black squares), in function of self reported stress among 15456 women residing in 95 of the 110 neighbourhoods in the city of Malmö. Women who reported not being stressed are compared with those who reported being stressed and those who abstained from answering this question.

\section{Key points}

- The study gives empirical support to the idea that contextual factors, related to aspects of the social environment in which people live in, contribute to differences in individual behaviour, such as medication use.

- The level of social participation in the neighbourhood, a main aspect within the concept of social capital, might be related to use of anxiolytic-hypnotic drugs (AHD), over and above individual low social participation, low educational level, and living alone.

- Low neighbourhood social participation may affect downstream individual characteristics, which in turn influence the use of AHD.

- Although neighbourhoods in Malmö are on average rather homogeneous regarding AHD use, they seem to play a part in explaining AHD use for certain groups of women, like for example those reporting stress.

association was, however, different for different neighbourhoods.

\section{DISCUSSION \\ Main findings}

Our results suggest that the level of low social participation in the neighbourhood may determine AHD use among women, over and above individual social participation, educational level, and living alone. This association was, however, reduced after additional adjusting for self reported stress, self rated health, disability pension, and use of medication for somatic disorders.

The observed weakening of the association between neighbourhood social participation and women's use of AHD after we adjusted for the individual health variables may be an expression for compositional confounding-that is, women with impaired health move to certain neighbourhoods. However, the observed reduction of the association may instead be telling us that these individual level variables were in the pathway between neighbourhood social environment and use of AHD. For instance, living in a deprived neighbourhood with low social participation may negatively affect individual social participation ${ }^{22}$ and health related behaviour, ${ }^{6}$ which in turn could have an impact on medication use. The neighbourhood environment may influence AHD use through diverse mechanisms like accessibility to health services ${ }^{2}$ and local practice habits of practitioner, ${ }^{23}$ normative attitudes towards medication use, transmission of health information, health behaviour norms, and social control of deviant health related behaviour. ${ }^{69}$ Our results suggest that general practitioners could be aware of the association between neighbourhood low social participation and AHD use. At a political level, it may be emphasised

\section{Policy implications}

- Our results suggest that general practitioners could be aware of the association between neighbourhood low social participation and AHD use.

- At a political level, it may be emphasised that low social participation in neighbourhoods seems to go hand in hand with higher use of AHD. 
that low social participation in neighbourhoods seems to go hand in hand with higher use of AHD.

Although neighbourhood social participation was associated with AHD use, individual AHD use was on average rather homogeneous all over the city of Malmö. That is, only $1.7 \%$ of the individual differences in the probability of using AHD seemed to have contextual reasons. In other words, there existed a collective phenomenon influencing AHD use, but it explained a minor part (only $1.7 \%$ ) of the individual variation in the propensity for using AHD.

In contrast with medication use, there existed a stronger clustering for some socioeconomic variables, like for example living alone, low educational achievement, and disability pension. The results of cross sectional multilevel analyses often demonstrate a higher neighbourhood clustering of socioeconomic and behavioural outcomes than of biological and medical variables. ${ }^{24}$ Probably, socioeconomic and behavioural variables are more susceptible to current contextual influences than life course determined biomedical variables. If contextual factors do affect biomedical outcomes, these effects need to be investigated by longitudinal, rather than cross sectional, multilevel analysis.

The random slope variance analysis suggested that the neighbourhood environment modified the association between certain individual level variables and AHD use. The impact of the neighbourhood on AHD use, as expressed by the ICC, was larger for stressed women and for those who abstained from answering this specific question on stress, than for women without stress. That is, in average, the neighbourhood level explained a modest part of the individual differences in the probability of using AHD, but this average measure hid larger neighbourhood effects for certain groups of women.

At this point, we will comment on the fact that the women with missing information on stress reported very similar AHD use as women reporting stress (that is, $9 \%$ and $10 \%$ respectively). It is possible, therefore, that women with missing information on this question were in fact women suffering from stress.

\section{Limitations: selection bias, information bias, and confounding}

The selection of geographical units should not be a source of selection bias, as we only left out the 15 least populated neighbourhoods. The participation rate (median; first-third quartile) in the MDCS in the different neighbourhoods was low $(42 \% ; 32 \%-50 \%)$. Hence, the cohort may not be representative for the whole female population, which may reduce the external validity of our results. However, participants could be regarded as fairly representative of the general population, at least in relation to the main sociodemographic variables. ${ }^{25}$

Information on drug use was self reported, which seems to be a valid method for measuring current drug use. ${ }^{12}$ The reliability (test-retest stability) of the social participation variable, as assessed in a previous paper, was rather high $(\kappa=0.70) .{ }^{26}$ Unfortunately, we had no information about how long the women had lived in their respective neighbourhoods, which would have given information about the exposure time of the specific neighbourhood rate of low social participation.

\section{Conclusions}

Our study gives empirical support to the idea that contextual factors related to aspects of the neighbourhood environment contribute to differences in individual behaviour, such as medication use..$^{27}$ In concrete, our results suggest that a low level of social participation in the neighbourhood, a main aspect within the concept of social capital, ${ }^{9}$ seems to be related to individual AHD use, over and above individual social participation, living alone, and educational level. In a multilevel way of thinking, neighbourhood social participation can be placed upstream in the causal pathway determining individual health and it may affect downstream individual characteristics, which in turn influence the use of AHD. ${ }^{28}$

However, neighbourhoods in Malmö are on average rather homogeneous regarding individual use of AHD (that is, the neighbourhood level explained $1.7 \%$ of the differences in the probability of using AHD). Nevertheless, neighbourhoods play a larger part in explaining AHD use for certain groups of women, like those reporting stress. This heterogeneity needs to be considered when analysing contextual effects on individual health. ${ }^{29}$

\section{ACKNOWLEDGEMENTS}

We wish to express our gratitude to Professor Göran Berglund for his support regarding the Malmö diet and cancer study database and to the NEPI foundation for its support regarding studies in social pharmacoepidemiology. We also wish to thank Min Yang at the Centre for Multilevel Modelling, Institute of Education, London for useful comments about multilevel modelling. This study was financed by the County of Skåne's Pharmacological council, by an ALF-government grant, Dnr M: E 39 390/98 (Juan Merlo), the NEPI foundation, the Swedish council for working life and social research, the Swedish Medical Research Council, the Swedish Cancer Society and National Institutes of Health (R01 HL71084-01).

\section{Authors' affiliations}

K Johnell, Family Medicine Stockholm, Karolinska Institutet, Huddinge, Sweden

J Merlo, Department of Community Medicine, Malmö University

Hospital, Lund University, Malmö, Sweden

J Lynch, Department of Epidemiology, School of Public Health Center for Social Epidemiology and Population Health, and Institute for Social

Research, University of Michigan, Ann Arbor, USA

G Blennow, The National Social Insurance Board, Stockholm, Sweden

\section{REFERENCES}

1 Imanaka Y, Araki S, Nobutomo K. Effects of patient health beliefs and satisfaction on compliance with medication regimens in ambulatory care at general hospitals. Nippon Eiseigaku Zasshi 1993;48:601-11.

2 Isacson D, Haglund B. Psychotropic drug use in a Swedish community--the importance of demographic and socioeconomic factors. Soc Sci Med 1988;26:477-83

3 Haaijer-Ruskamp FM, Hemminki E. The social aspects of drug use. WHO Reg Publ Eur Ser 1993:45:97-124

4 Ashton H, Golding JF. Tranquillisers: prevalence, predictors and possible consequences. Data from a large United Kingdom survey. $\mathrm{Br} J$ Addict 1989;84:541-6.

5 Emmons KM. Health behaviors in a social context. In: Berkman LF, Kawachi I, eds. Social epidemiology. New York: Oxford University Press, 2000:242-66.

6 Macintyre S, Ellaway A. Ecological approaches: rediscovering the role of the physical and social environment. In: Berkman LF, Kawachi I, eds. Social epidemiology. New York: Oxford University Press, 2000:332-48.

7 Groenewegen PP, Leufkens HG, Spreeuwenberg P, et al. Neighbourhood characteristics and use of benzodiazepines in the Netherlands. Soc Sci Med 1999;48:1701-11.

8 Woolcock M, Deepa N. Social capital: implications for development theory, research and policy. World Bank Res Obs 1999;Feb.

9 Kawachi I, Berkman LF. Social cohesion, social capital, and health. In: Berkman LF, Kawachi I, eds. Social epidemiology. New York: Oxford University Press, 2000:174-90.

10 Berkman LF. Assessing social networks and social support in epidemiologic studies. Rev Epidemiol Sante Publique 1987;35:46-53.

11 Berglund G, Elmstahl S, Janzon L, et al. The Malmo Diet and Cancer Study. Design and feasibility. J Intern Med 1993;233:45-51.

12 Merlo J, Berglund G, Wirfalt E, et al. Self-administered questionnaire compared with a personal diary for assessment of current use of hormone therapy: an analysis of 16,060 women. Am J Epidemiol 2000;152:788-92.

13 WHO Collaborating Centre for Drug Statistics Methodology. Norwegian Institute of Public Health. (http://www.whocc.no/atcddd/).

14 Capella D. Descriptive tools and analysis. WHO Reg Publ Eur Ser 1993;45:55-78.

15 Sweden Statistics. Living conditions. Isolation and togetherness - an outlook on social participation 1976, Report no 18. Stockholm: Sweden Statistics, 1980.

16 Snijders T, Bosker R. Multilevel analysis - an introduction to basic and advanced multilevel modeling. Thousand Oaks, CA: Sage, 1999.

17 Rice N, Leyland A. Multilevel models: applications to health data. J Health Serv Res Policy 1996;1:154-64. 
18 Leyland A, Goldstein H. Multilevel modelling of health statistics. Chichester: Wiley, 2001.

19 Goldstein H, Browne W, Rasbash J. Partitioning variation in multilevel models. London: Multilevel Models Project, Institute of Education, (http:// multilevel.ioe.ac.uk/team/materials/pvmm.pdf).

20 Browne W, Subramanian S, Jones K, et al. Variance partitioning in multilevel logistic models that exhibit over-dispersion. London: Multilevel Models Project, Institute of Education, (http://multilevel.ioe.ac.uk/team/materials/ vpmlmeo.pdf).

21 Rasbash J, Browne W, Goldstein H, et al. A user's guide to MLwiN. Version 2. 1. London: Multilevel Models Project, Institute of Education, University of London, 2000.

22 Lindstrom M, Merlo J, Ostergren PO. Individual and neighbourhood determinants of social participation and social capital: a multilevel analysis of the city of Malmo. Sweden, Soc Sci Med 2002;54:1779-91.

23 Melander A, Henricson K, Stenberg P, et al. Anxiolytic-hypnotic drugs: relationships between prescribing, abuse and suicide. Eur J Clin Pharmacol 1991;41:525-9.
24 Ukoumunne OC, Gulliford MC, Chinn S, et al. Methods for evaluating areawide and organisation-based interventions in health and health care: a systematic review. Health Technol Assess 1999;3:iii-92.

25 Manjer J, Carlsson S, Elmstahl S, et al. The Malmo Diet and Cancer Study: representativity, cancer incidence and mortality in participants and nonparticipants. Eur J Cancer Prev 2001;10:489-99.

26 Hanson BS, Ostergren PO, Elmstahl S, et al. Reliability and validity assessments of measures of social networks, social support and control--results from the Malmo Shoulder and Neck Study. Scand J Soc Med 1997:25:249-57.

27 Merlo J, Lynch J, Yang M, et al. Effect of neighborhood social participation on individual use of hormone replacement therapy and anti-hypertensive medication: a multilevel analysis. Am J Epidemiol 2003;157:774-83.

28 Kaplan GA. What is the role of the social environment in understanding inequalities in health? Ann N Y Acad Sci 1999:896:116-19.

29 Merlo J. Multilevel analytical approaches in social epidemiology: measures of health variation compared with traditional measures of association. J Epidemiol Community Health 2003;57:550-2. 